\title{
A Review on Green Concrete Using Low-Calcium Pond Ash as Supplementary Cementitious Material
}

\author{
K.Yuvaraj ${ }^{1 *}$, S.Ramesh ${ }^{2}$ \\ ${ }^{I}$ Assistant Professor\& Civil Engineering \& K.S. Rangasamy College of Technology, Tiruchengode, Tamil Nadu, India. \\ ${ }^{2}$ Professor\& Civil Engineering \& K.S. Rangasamy College of Technology, Tiruchengode Tamil Nadu, India. \\ *Corresponding author E-Mail ID: yuva02raj@gmail.com \\ Doi: https://doi.org/10.34256/irjmtcon47
}

\begin{abstract}
Nowadays, the construction cost is very high with the use of crucial material such as cement, fine aggregate and coarse aggregate. This study includes the use of Pulverized fuel ash waste materials as partial replacement of cement and fine aggregate. Industries in India produce a large amount of waste such as fly ash, Bottom ash, Pond ash, etc., that can be useful in the partial replacement of all raw materials due to their different properties. Therefore, we study the number of useful research documents in this field and try to improve with locally available waste material can be proven economical as well. The objective of this study was to determine the environmental impacts of open dumping of pond ash around a thermal power plant.
\end{abstract}

Keywords: Waste Material, Fly ash, Bottom ash, Pond ash, Environmental Impact, thermal Power Plant Economical.

\section{INTRODUCTION}

\section{Cement and Concrete:}

The name Portland cement was given by Joseph Aspidin 1824 due to its similarity in color and its quality when hardens like Portland stone. It can be defined as the bonding material having cohesive and adhesive properties which makes it capable to unite the different construction materials and form the compacted assembly. It is a major contributor to $\mathrm{CO}_{2}$ emissions as an estimated 5 to $8 \%$ of all human generators atmospheric $\mathrm{CO}_{2}$ worldwide comes from the concrete industry. The primary chemical components of ordinary Portland cement are calcium, alumina, silica, iron. The raw materials required for cement production are nonrenewable and are depleting at a rapid rate. But at the same time, a number of industrial and agro wastes with inherent cementations properties are produced abundantly. But they are mostly disposed into landfills. Retain such byproducts as alternates for cement has various benefits including conservation of the environment, the sustainability of resources and solving the disposal problem of by-products. Particularly in India, with the ever-growing demand for cement to serve the rapidly developing constructions and infrastructure projects, the impact created by OPC on the environment is massive. Hence, there is an immediate necessity to control the usage of OPC by developing potential alternates for it. In that context, extensive researches are being carried out around the world in analyzing the possibilities of using substitute materials for OPC concrete.

Concrete is a construction material commonly used in the world. Conventional concrete is a mixture of cement, fine aggregate, Coarse Aggregate, and water. Compared to all other 
ingredients, the aggregates occupy 75 to $80 \%$ of the total volume of concrete and affect the fresh and hardened properties of the concrete. In the total composition of the concrete, 25 to $30 \%$ was contracted by the fine aggregate in volume. The quality of the concrete is determined due to its mechanical properties. The mechanical properties are mainly divided into short and long term properties. The compressive strength, the divided tensile strength, the modulus of elasticity and the flexural strength are short-term properties. Porosity and impermeability are long-term properties.

\section{PROCESS OF PULVERIZED FUEL ASH PRODUCTION:}

Coal-fired power plants are the main source of power generation in India and coal. The ashes are the by-products of these thermal power plants. The Indian coal reserve is about 200 billion of tons and its annual production reaches approximately 250 million tons. In India, unlike most developed countries, the ash content in coal used for power generation is around 30 to $40 \%$. The generation of ash has increased to about 131 million tons during 2010- 11 will continue to increased. The finest ash particles are carried by the combustion gas to the electrostatic precipitators and are called fly ash, while the coarse ash particles fall to the bottom of the boiler and are referred to as bottom ash. Mainly, the fly ash is removed using a dry or wet disposal scheme. In a dry state, the fly ash is transported by truck, Gutter or conveyor on-site and discarded by the construction of a dry embankment (dike). In wet removal, fly ash and bottom ash are transported as sludge through the pipeline and removed off in the ash pond is called an ash pond. Most power plants in India use wet disposal systems, and when the lagoons are full, there are four basic options available: (a) build new lagoons using conventional construction material, (b) transportation of fly ash from existing lagoons to another disposal site, (c) elevate the existing dike using conventional construction material, and (d) elevate the dam using fly ash dug in the lagoon ("ash dam"). The option of raising the existing dike is very profitable because any fly ash used to build dike in addition to saving the cost of landfilling, it would improve the capacity of the lagoon to be eliminated. Further, it is observed that the failure of ash pond, which results in major damage to the environment, is mainly due to ineffective functioning of filters. Such a huge quantity does pose challenging problems, in the form of land usage, health hazards, and environmental dangers. Both in disposal, as well as in utilization, the utmost care has to be taken, to safeguard the interest of human life, wildlife, and environment.

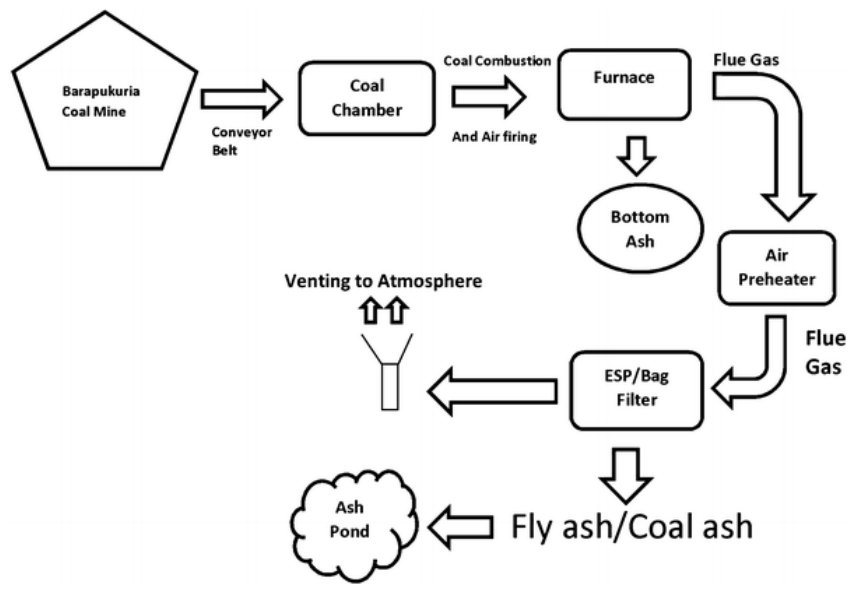

Fig 1: Process of pulverized fuel ash production

\section{ENVIRONMENTAL PROBLEM USING POND ASH:}

The production of ash from thermal power plants has increased from 17.06 million tons during 1990-1991 to 68.82 million tons in 1996-1997 and has crossed 100 million tons in the year 
2000. The ashes must be handled properly or not, it will cause pollution of the earth, air, and water. There is a serious concern to use it to the fullest. If the pond ash is not used correctly or is discarded from the power plant site problems may arise due to the storage of waste material. Therefore, pond ash as a by-product of waste material, if the shortage of fine aggregate supplements (river sand) in mortar and concrete, reduces the demand for elimination of waste from thermal power plants, reduces its environmental impact with due use of large amounts of waste in the construction industry which can be used for alternative material in concrete, as an industrial by-product. It is also a social thing researchers' responsibility to promote the beneficial use of industrial by-products. To preserve natural resources, conserve energy and reduce or eliminate the need for industrial waste disposal in landfills.

\section{PHYSICAL PROPERTIES OF POND ASH:}

The physical properties of pond ash are given in table .1

Table.1 Physical properties of pond ash

\begin{tabular}{|c|c|c|}
\hline Sl.No & Properties & Values \\
\hline 1 & Specific gravity & 2.63 \\
\hline 2 & Fineness $\left(\mathrm{m}^{3} / \mathrm{kg}\right)$ & 2.95 \\
\hline 3 & Colour & Light Gray \\
\hline 4 & Shape & Rounded /Sub Rounded \\
\hline
\end{tabular}

\section{CHEMICAL COMPOSITION OF POND ASH:}

The chemical properties of pond ash are given in table .2

Table.2 Chemical properties of Pond ash

\begin{tabular}{|c|c|c|}
\hline SI. No & Constituents & Value(\%) \\
\hline 1 & $\mathrm{Al}_{2} \mathrm{O}_{3}$ & 43.56 \\
\hline 2 & $\mathrm{SiO}_{2}$ & 41.67 \\
\hline 3 & $\mathrm{CaO}$ & 0.73 \\
\hline 4 & $\mathrm{Fe}_{2} \mathrm{O}_{3}$ & 8.27 \\
\hline 5 & $\mathrm{~K}_{2} \mathrm{O}$ & 3.11 \\
\hline 6 & $\mathrm{TiO}_{2}$ & 1.32 \\
\hline 7 & $\mathrm{MnO}$ & 0.1 \\
\hline
\end{tabular}

\section{LITERATURE REVIEW:}

Agawam et al. presented the properties of the bottom ash as substitution of fine aggregate in concrete. The workability of concrete it decreases with the increase in ash content of the bottom due to the increase in water which was incorporated by increasing the superplasticizer content. The density of the concrete decreased with the increase in the bottom ash content due to the low specific gravity of the bottom ash compared to the fine aggregates. Compressive strength, tensile strength, and resistance to fine bending the aggregates replaced the bottom ash concrete samples were lower than the control Specimens specific to all ages. A replacement of $30 \%$ and $40 \%$ mixture containing the ash, at 90 days, reaches the compressive strength equivalent to $108 \%$ and 
$105 \%$ compressive strength of normal concrete at 28 days and reaches flexural strength in the range of $113-118 \%$ at 90 days of flexural strength of normal concrete at 28 days. Concrete bottom ash achieves split tensile strength in the range of $121-126 \%$ at 90 days of traction division resistance of normal concrete at 28 days. Concrete containing $50 \%$ bottom ash was acceptable for most structures. [1]

MohdSyahrul et al. represented the results on the properties of the special concrete using washed bottom ashes partial replacement of sand. Bottom ash with $10 \%$ cement replacement by weight. It was not suitable for concrete because it has produced concrete with less resistance. In the early ages that can lead to ruptures during construction. 30\% of the WBA the replacement for the fine aggregate was found to be the optimal amount in order to obtain a favorable force and a good pattern of force development on the increased ages. [2]

Seung Bum Park et al. studied mechanics properties of porous concrete that uses coarse aggregates from the coal bottom. The chloride content of the coal bottom ash aggregate met the standard permissible values when washed more than twice. The compressive and the resistance to flexion tended to decrease in all aggregate grades such as coal increase in the proportion of ash mixture in the bottom. When the fly ash and coal bottom ash were mixed and even though the proportion of bottom ash mixture was $20 \%$, the compressive strength increased approximately $0.5 \%$ at the age of 90 days. [3]

Kou Shi-Cong and Poon Chi-Sun reported the properties of concrete prepared with crushed stone, bottom and fine ash recycled aggregates as fine aggregates. When the same $\mathrm{W} / \mathrm{C}$ ratio is used the compressive strength of FBA and FRA concrete decreased to all ages with an increase in the contents of FBA and FRA. This may be due to the high initial free water content used in the bleeding mixtures and the poor interfacial bond between aggregates and cement pastes. In a fixed $\mathrm{W} / \mathrm{C}$, the compressive strength decreased with the increase of the fine lower ash content. Fine recycled aggregate decreased compression strength of concrete. [4]

Malkit Singh and Rafat Siddique reported the results of the effect of coal bottom ash as partial relocation of sand in the properties of concrete. The published research literature shows that strength the development pattern of the bottom ash concrete is similar to that of the conventional one. Concrete but there is a decrease in strength in all ages of curing. The reduction in the strength of the concrete is mainly due to the greater porosity and water. Demand on the use of bottom ash in concrete. The compressive strength can be improved by reducing water demand through the use of superplasticizers. [5]

Malkit Singh and Rafat Siddique discussed the results of properties of resistance and microstructural properties of concrete containing coal bottom ash as partial replacement of fine aggregate. The workability of the concrete of the bottom ash decreased with the use of the coal bottom ash in partial or total replacement of river sand in concrete. The values of the bottom ash concrete decreased with the increase in sand levels. The complicated shape and texture of the coal bottom ash particles have also contributed to increasing the inter friction of particles and therefore the decrease in the workability of concrete. [6]

Andrade et al. reported the influence of coal bottom ash as fine aggregate on fresh properties of concrete. The high porosity of the lower ash means that the $\mathrm{w} / \mathrm{c}$ ratio of the concrete cannot be taken as accurate. The water absorbed internally by the bottom ash was released to the concrete. The presence of bottom ash increased the amount of water loss by bleeding, the bleeding time and also the rate of water release, and the higher the content of bottom ash of concrete is greater this effect. [7]

Kim et al. reported the mechanical characteristics of the normal and high strength mortar that incorporates fine bottom ash aggregates the mortar with fine bottom ash aggregates was lighter than the mortar with the fine natural aggregates, regardless of the $\mathrm{W} / \mathrm{B}$ due to the lighter 
specific one's gravity and porous structures of FBA aggregates. The relative values of compressive strength were in a range of 80 to $95 \%$, while compressive strength of the reference specimen (mortar with NF aggregates) was in a range of 40-90 MPa. It can be said that the higher the porosity and greater W / B in the mortar with aggregates of FBA resulted in lower resistance to compression compared to the mortar with NF aggregates. [8]

TurhanBilir presented the report on the effects of non-field. Slag and bottom ash as fine aggregate on the permeability of the concrete. Properties Concretes with replacement ratios of $10 \%, 20 \%$, and $30 \%$ have losses of force lower than the reference. All groups are durable against permeability to chloride. Unground ground coal ash can be used at $30 \%$ proportion to produce very low permeable concrete. [9]

Ashis Kumar Bera had reported on compaction characteristics of the ash pond. Three types of pond ash have been chosen to investigating the effects of compaction energy, moisture content and specific effects gravity. The relationship between the dry density and the moisture content for a particular pond the ash is linear. Based on the experimental results, a linear relationship has been developed between dry density, specific gravity, and moisture content. [10]

HaldunKurama and Mine Kaya studied the use of coal ashes of combustion bottom in the concrete mixture. In concrete trials, although the resistance to compression and bending of the cured samples at 56 days of increase with the increase in the amount of ash replacement up to $15 \%$, the maximum replacement The CBA rate was determined as $10 \%$. When $10 \%$ of CBA is replaced by cement, the compressive strength of CBA concrete increases from $42.65 \mathrm{~N} / \mathrm{mm} 2$ to $45.1 \mathrm{~N} / \mathrm{mm}^{2}$. The observed C-S-H fibers or an elongated particle in the SEM micrograph of BC10 clearly indicates the pozzolanic effect of ACB. Replacement in the improvement of the strength of the concrete. [11]

Isa Yuksel et al. showed the durability of concrete incorporating unground ground blast furnace slag and bottom ash as fine aggregate. The effects of BA and GBFS, as fine aggregate in the durability of the concrete, were investigated. As a general result, GBFS and BA affect durability properties concrete positively when used as a fine aggregate. Compressive strength loss due to freezing-thawing effect decreases for low replacement ratio (10-30\%). GBFS or BA replaced concrete has better durability than reference concrete.BA, used as fine aggregate, increases the degree of porosity of concrete. GBFS also increases porosity but this increment occurs less than BA. [12]

Geetha and Ramamurthy presented their research on reuse potential of bottom ash with low calcium content as added through palletization. The binder content, moisture requirements and their interaction effect are the significant factors to achieve maximum palletization efficiency. They suggested that instead of using commercially available clays such as bentonite and metakaolin, you can use normal clay with a plasticity index greater than 75 as a binder for the production of bottom ash aggregates with the low calcium content. [13]

Bai \& Basheer studied the usage of bottom ash in concrete focused on its potential to partially replace fine aggregate due to its similar particle size to that normal sand. The similar particle size replacement reasonably reduces the sand. The minimum quantity of bottom ash requires a feeble reduction in sand utilization. [14]

Sushilkumar investigated that effect of the addition of pond ash on the workability of concrete for $20 \%, 40 \%, 60 \%$ and $80 \%$ of the fine aggregate replaced with pond ashes with additional cement and additional water to restore workability Fly ash replacement provide better workability for several dimensions. He estimated that a maximum of $40 \%$ of the fine aggregate can be replaced with pond ash with the addition of $30 \%$ additional cement that then they generally lead to unprofitable blends. [15] 
Chai Jaturapitakkul and Raungraut Cheer rot reported that the bottom ash has a high potential to become a good pozzolónico material. This will produce the quality of the sensitive cement and the quality of the rough concrete. The consumption of cement content, workability, resistance to compression and cost of the researchers also studied concrete made with pond ash. [16]

Siddique conducted a study on behavior and long-term durability of compacted concrete made in the laboratory, which contains bottom ash as fine aggregate for properties such as strength, stiffness, and deformation. It was observed that the samples containing dry bottom ash offered excellent properties of resistance, rigidity, and deformation, considering the range of the cement factors used. [17]

Vladimir Kouprianov and Vladimir Bashkin reported that the chemical contents such as toxic elements, heavy metals, and natural levels. Radioactivity in coal ash greatly influences the environment and ecological system. Trace metals present in a small fraction of coal ash, can leach and contaminates the soil, as well as surface and underground water resources. [18]

Bapat et al. studied the compressive strength of concrete. It contains high volumes of pond ash as a substitute for cement. Also, Portland concrete cement and concrete made with fly ash were compared. It was also it is inferred that the pond ashes were used successfully in large volumes to make concrete of lesser strength. [19]

TrakoolAramraks reported that bottom ash required water content approximately 25 to $50 \%$ more than normal concrete to obtain suitable workability Also, the bottom ash concrete has better permeability of than normal concrete. [20]

Aggarwal et al. observed that the workability of concrete decreased with the increase in bottom ash mixture due to an increase in water demand The quality concrete of the concrete is deprived. [21]

Ratchayut Kasemchaisir \& Somnuk Tangtermsirikul reported that durability, chloride ion permeability, carbonation depth and shrinkage in drying with $10 \%$ bottom ash were larger than those of the controlled concrete. [22]

MohdSyahrul et al. reported that sieve analysis on washed bottom ash which is more suitable for mortar rather than sand in concrete. These concrete properties are more trivial. [23]

Kim \& Lee carried out a detailed experimental investigation to evaluate the effect of fine and coarse bottom ash on flow characteristics and density of the concrete mixture. It was found that both fine and coarse the aggregates of bottom ash had more influence on the flexural strength than compressive strength. Other concrete properties must be validated with concrete production in real-time. [24]

Mangaraj has evaluated that pond ash is potentially usable, but it is variable in its characteristics, due to the differences in the unit weight of fly ash and bottom ash. The pond ash is deposited at about $100 \mathrm{~m}$ of the discharge point of the ash suspension in the pond is thicker ash compared to the ash deposited at a distance of $100 \mathrm{~m}$ between these two areas is of average particle size. [25]

Ranganath concentrated on several types and sources of carbon, Performance of the generation facility, variation in the collection, disposal, storage. methods, the temperature of burning coal and some other issues control the Properties of pond ashes. The characterization of the pond ashes guarantees suitability. For the manufacture of concrete [26]

Triches et al. studied on the bottom ash is the thickest material that falls in the bottom of the furnace in the large modern thermal power plants. and they constitute approximately $20 \%$ of the total ash content of the coal fed into the boilers. Background ash is seldom used in concrete 
due to its inactive pozzolanic reaction. The bottom ash could be incorporated by replacing the fine aggregate content. The benefits of the environment would not only come from the use of waste material, but also to the lower demand for natural fine aggregate. [27]

Sarkar et al. conducted studies using pond ash in combination with local clay for the manufacture of bricks. The clay is mixed with the two different ashes in the range of $10 \%$ to $90 \%$, hydraulically pressed and fired at $1000^{\circ} \mathrm{C}$. The comparative study, in general, showed that the ash-clay. The bricks were of superior quality with greater water absorption to the conventional products. [28]

Naganathan et al. the studies carried out with the bottom ash is a class $\mathrm{C}$ because the sum is less than $70 \%$ but higher than $50 \%$. Class $\mathrm{C}$ is generated from the combustion of lignite or subbituminous coal with high calcium content smaller percentages of potassium, magnesium, sodium is also present in the bottom ash of the Malaysian power plant with traces of barium, manganese, and zinc. BS 3892: Part 1: 1993 specified an SO3 content of less of $2.5 \%$ and a maximum of 5.0\% by ASTM C618 and alkali Na2O of no more than 1.5\%. [29]

Lee Bong Chun et al. presented an article about the study of the fundamental properties of concrete incorporated with pond ash in Korea. He also expressed that the pond ashes must be used to identify their quality, which differs greatly according to the disposal sites that are produced. [30]

Vidya et al. conducted an experimental research on burnt pond ashes of clay bricks. The raw materials used for the manufacture of the bricks were. ashes, fly ash, lime, plaster, and sand. Modular samples of brick size. They were molded $230 \mathrm{~mm}$ x $110 \mathrm{~mm}$ x $75 \mathrm{~mm}$ according to IS 12894-2002 using several mix proportions. The resistance to compression of the bricks observed. Varied from 9.2 to $7.6 \mathrm{~N} / \mathrm{mm}^{2}$. Cracks were observed in the walls with these bricks. [31].

\section{REFERENCES:}

1. Aggarwal, P, Aggarwal, Y \& Gupta, SM 2007, „Effect of Bottom Ash as replacement of Fine Aggregate in Concrete ${ }^{e c}$ Asian journal of civil engineering (Building and Housing), vol. 8, no. 1, pp. 49-62

2. MohdSyahrul, Hisyam bin Mohd Sani, FadhluhartinibtMuftah\&ZulkifliMuda 2010, „The Properties of Special Concrete Using Washed Bottom Ash as Partial Sand Replacemente, International Journal of Sustainable Construction Engineering Technology, vol. 2, pp. 65-76.

3. Seung Bum Park, Young Il Jang*, Jun Lee, Byung Jae Lee 2009, An experimental study on the hazard assessment and mechanical properties of porous concrete utilizing coal bottom ash coarse aggregate in Korea, Journal of Hazardous Materials, PP. 348-355, DOI: 10.1016/j.jhazmat.2008.11.054

4. Kou Shi-Cong, Poon Chi-Sun 2009, Properties of concrete prepared with crushed fine stone, furnace bottom ash and fine recycled aggregate as fine aggregates, Construction and Building Materials, Vol.23 PP 2877-2886, DOI: 10.1016/j.conbuildmat.2009.02.009

5. Malkit Singh, Rafat Siddique 2015, Effect of coal bottom ash as partial replacement of sand on workability and strength properties of concrete, Journal of Cleaner Production, PP 1-11, http://dx.doi.org/10.1016/j.jclepro.2015.08.001

6. Malkit Singh, Rafat Siddique 2014, Strength properties and micro-structural properties of concrete containing coal bottom ash as partial replacement of fine aggregate, Vol 50, PP 246256, http://dx.doi.org/10.1016/j.conbuildmat.2013.09.026 
7. Andrade, LB, Rocha, JC \&Cheriaf, M 2009, „Influence of Coal Bottom Ash as Fine Aggregate on Fresh Properties of Concrete ${ }^{e e}$, Construction and Building Materials, vol. 23, pp. 609-614

8. H.K. Kim, J.H. Jeon, H.K. Lee 2012, Flow, water absorption, and mechanical characteristics of normal and high-strength mortar incorporating fine bottom ash aggregates, Construction and Building Materials, Vol 26, PP 249-256, DOI: 10.1016/j.conbuildmat.2011.06.019

9. TurhanBilir 2012, Effects of non-ground slag and bottom ash as fine aggregate in concrete permeability properties, Construction and Building Materials, Vol 26, PP 730 -734, DOI: 10.1016/j.conbuildmat.2011.06.080

10. Ashis Kumar Bera 2007, „Compaction Characteristics of Pond ash"e, Journal of Materials in Civil Engineering, vol. 19, no. 4, pp. 349-357.

11. HaldunKurama, Mine Kaya 2008, Usage of coal combustion bottom ash in the concrete mixture, Construction and Building Materials, Vol 22, PP. 1922-1928, DOI: 10.1016/j.conbuildmat.2007.07.008

12. Isayuksel, TurhanBilir, Omer Ozkan 2007, Durability of concrete incorporating non-ground blast furnace slag and bottom ash as fine aggregate, Building and Environment, Vol 42 PP 2651-2659, DOI: 10.1016/j.buildenv.2006.07.003

13. S. Geetha, K. Ramamurthy 2010, Reuse potential of low-calcium bottom ash as aggregate through palletization, Waste Management Vol 30, PP 1528-1535, DOI: 10.1016/j.wasman.2010.03.027.

14. Bai, Y \& Basheer 2003, „Influence of Furnace Bottom Ash as Fine Aggregate on Properties of Concretee $^{\text {ee }}$ Structures and Buildings. vol. 156, no. 1, pp. 85-92.

15. Sushilkumar 1992, „Use of Fly Ash as Fine Aggregate in Concrete Engineering, Delhi College of Engineering, University of Delhi, Delhi.

16. Chai Jaturapitakkul\&RaungrutCheerarot 2003, „Development of Bottom Ash as Pozzolanic material $^{e e}$, Journal of materials in civil engineering, vol. 15, pp. 48-53.

17. Siddique, R 2004, „Performance Characteristics of High Volume Class F Fly Ash Concrete Cement and Concrete Research, vol. 33, no.3, pp.487-493.

18. Vladimir Kouprianov\& Vladimir Bashkin 2000, „Environmental Impact of Heavy Metals Contained M Fly Ash Emitted from the Thai Lignite Fired Power Plant ${ }^{e e}$, ASC Div Fuel Chem, vol. 45, no. 1, pp. 83-87.

19. Bapat, JD, Sabnis, SS, Hazaree, CV \&Deshchowgule, AD 2006, „Eco-friendly Concrete with High Volume of Lagoon Ash, " Journal of Material in Civil Engineering ASCE, pp. 453-461

20. TrakoolAramraks 2006, „Experimental Study of Concrete Mix with Bottom Ash Fine Aggregate in Thailand ${ }^{\text {ee }}$, Seameo-Innotec.

21. Aggarwal, P, Aggarwal, Y \& Gupta, SM 2007, „Effect of Bottom Ash as Replacement of Fine Aggregate in Concrete ${ }^{e e}$ Asian journal of civil engineering (Building and Housing), vol. 8, no. 1, pp. 49-62.

22. RatchayutKasemchaisir\&SommnukTangtermsirikul 2008, „Properties of Self-Compacting Concrete Incorporating Bottom ssh as a Partial Replacement of Fine Aggregate , Science $^{\text {ee }}$ Asia, vol. 34, pp. 87-95.

23. MohdSyahrul, Hisyam bin Mohd Sani, FadhluhartinibtMuftah\&ZulkifliMuda 2010, „The Properties of Special Concrete Using Washed Bottom Ash as Partial Sand Replacemente, International Journal of Sustainable Construction Engineering Technology, vol. 2, pp. 65-76. 
24. Kim, HK \& Lee, HK 2011, „Use of Power Plant Bottom Ash as Fine and Coarse Aggregates in High Strength Concrete ${ }^{e e}$, Construction and Building Materials, vol. 25, pp.1115-1122.

25. Mangaraj, BK 1994, „Use of Ponded Fly Ash as Part of Replacement of Fine Aggregate in Mortar and Concrete ${ }^{e e}$ ICJ, pp. 279-282.

26. Ranganath, R V 1995, „A Study on the Characterization and use of Ponded Fly Ash as Fine Aggregate in Mortar and Concrete ${ }^{e e}$ Ph.D. Thesis, report, IITD-Delhi.

27. Triches, G, Pinto, RCA \& Silva, AJ 2006, „Evaluation of Roller Compacted Concrete Pavement with Bottom Ash by Ultrasound Measurements-An Experimental Study, 5th international conference on research and practical applications using wastes and secondary materials in pavement Engineering, Livepool, UK, vol. 2.

28. Ritwik Sarkar 2007, „Effect of Addition of Pond Ash and Fly ash on properties of Ash-Clay Burnt Brickse, Journal - Waste Management \& Research, ISSN 0734-242X, vol. 25, pp. 566571.

29. Naganathan, S, Razak HA \&Nadzrian, AH 2010, „Effect of Kaolin Addition on the Performance of Controlled Low Strength Material Using Industrial Waste Incineration Bottom $\mathrm{Ash}^{\mathrm{ee}}$, Waste Management and Research, pp. 28848-28860.

30. Lee Bong Chun, Kim Jin Sung, Kim JacSarg\&ChaeSeorig Tac 2008, „A Study on the Fundamental Properties of Concrete in Corporating Pond ash in Korea ${ }^{\text {ee }}$ The 3rd ACF International Conference.

31. Vidya, K, Kandasamy, S, SanjanaMalaimagal, U, Karthikeyan, SR, SathickBasha, G \& Tariq Junaid, H 2013, „Experimental Studies on Pond Ash Brickee, International Journal of Engineering Research and Development e-ISSN: 2278-067X, p-ISSN: 2278-800X, no. 5, pp. 06-11.

32. IS 3812 (Part 1): 2003, Pulverised fuel ash - Specification,Bureau of Indian Standards New Delhi. 